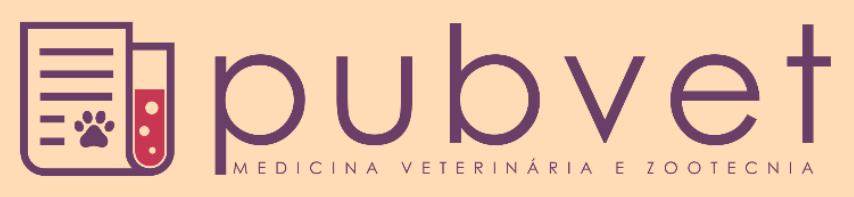

https://doi.org/10.31533/pubvet.v14n7a604.1-7

\title{
Fisioterapia pós-operatória em cão com hérnia cervical e suspeita de meningoencefalite granulomatosa associada
}

\author{
Daniela Loureiro Henrique ${ }^{1 *} \theta$, Beatriz Ribeiro Gaspar $^{2} \theta$, Emerson Siqueira ${ }^{3}$, Nadja Jorge ${ }^{4}$, \\ Luigi Milanez Ávila Dias Maciel ${ }^{30}$
}

${ }^{1}$ Pós-graduanda do curso de Medicina Veterinária da Universidade Santo Amaro. São Paulo-SP, Brasil.

${ }^{2}$ Discente do curso de Medicina Veterinária da Universidade de São Paulo. São Paulo - SP, Brasil. ${ }^{3} P o ́ s-$ graduando do curso de Medicina Veterinária da Universidade Júlio de Mesquita UNESP-SP.

${ }^{4}$ Médica Veterinária autônoma com especialização em Neurologia Veterinária.

*Autor para correspondência, E-mail: daniela@pataepatela.com.br

Resumo. A doença do disco intervertebral (DDIV) é um dos principais transtornos neurológicos em cães. Os sinais clínicos e o prognóstico podem variar de acordo com a localização da lesão, tipo de herniação, tempo de evolução, morosidade na realização da intervenção cirúrgica e comportamento do paciente. Normalmente, as lesões em região cervical costumam causar um quadro clínico grave, como hiperalgesia refratária a tratamento medicamentoso até tetraparesia. Nesses casos, a intervenção cirúrgica é a modalidade terapêutica de escolha. Os exames padrão ouro para o diagnóstico de DDIV são a ressonância magnética e a mielotomografia. A meningoencefalomielite granulomatosa (MEG) é uma doença inflamatória que acomete o encéfalo e/ou a medula espinhal. Ela pode causar lesões focais ou multifocais podendo atingir até o tronco encefálico. A fisioterapia tem papel importante tanto na recuperação do paciente submetido à cirurgia cervical pois contribui com o controle do edema local, acelera a cicatrização tecidual, recupera a força muscular e estimula a função neuromuscular, quanto no paciente com um quadro de MEG, pois auxilia no controle postural, no equilíbrio e na marcha.

Palavras chave: cães, meningomielite granulomatosa, reabilitação veterinária

\section{Postoperative physiotherapy in dog with cervical hernia and suspected associated granulomatous meningoencephalitis}

\begin{abstract}
Intervertebral disc disease is one of the main neurological disorders in dogs. The clinical signs and prognosis may vary according to the location of the lesion, type of herniation, time of evolution, delay in performing the surgical intervention and the patient's behavior. Usually, lesions in the cervical region usually cause a severe clinical picture, such as hyperalgesia refractory to drug treatment until tetraparesis. In these cases, surgical intervention is the therapeutic modality of choice. The gold standard exams for the diagnosis of DDIV are magnetic resonance and myelotomography. Granulomatous meningoencephalomyelitis is an inflammatory disease that affects the brain and / or spinal cord. It can cause focal or multifocal injuries and can even reach the brain stem. Physiotherapy plays an important role both in the recovery of patients undergoing cervical surgery as it contributes to the control of local edema, accelerates tissue healing, restores muscle strength and stimulates neuromuscular function, and in the patient with a Granulomatous meningoencephalomyelitis condition, as it helps in postural control, balance and gait.
\end{abstract}

Keywords: dogs, granulomatous meningomyelitis, veterinary rehabilitation 


\title{
Fisioterapia postoperatoria en perro con hernia cervical y meningoencefalitis granulomatosa asociada
}

\begin{abstract}
Resumen. La enfermedad del disco intervertebral (DDIV) es uno de los principales trastornos neurológicos en los perros. Los signos clínicos y el pronóstico pueden variar según la ubicación de la lesión, el tipo de hernia, el tiempo de evolución, el retraso en la realización de la intervención quirúrgica y el comportamiento del paciente. Por lo general, las lesiones en la región cervical generalmente causan un cuadro clínico grave, como la hiperalgesia refractaria al tratamiento farmacológico hasta la tetraparesia. En estos casos, la intervención quirúrgica es la modalidad terapéutica de elección. Los exámenes estándar de oro para el diagnóstico de DDIV son la resonancia magnética y la mielotomografía. La meningoencefalomielitis granulomatosa (MEG) es una enfermedad inflamatoria que afecta el cerebro y / o la médula espinal. Puede causar lesiones focales o multifocales e incluso puede llegar al tronco encefálico. La fisioterapia desempeña un papel importante tanto en la recuperación del paciente sometido a cirugía cervical como contribuye al control del edema local, acelera la curación del tejido, recupera la fuerza muscular y estimula la función neuromuscular, y en el paciente con una condición MEG, ya que ayuda en control postural, equilibrio y marcha.
\end{abstract}

Palabras clave: perros, meningomielitis granulomatosa, rehabilitación veterinaria

\section{Introdução}

Hansen tipo I é o nome dado a extrusão do disco intervertebral, responsável por causar compressão abrupta da medula espinhal pela herniação do núcleo pulposo (Hansen, 1952; Taylor, 2015). Quando acomete a região cervical, os sinais clínicos são encontrados nos quatro membros e vão desde a perda de propriocepção até a paralisia com perda de dor profunda, dependendo do grau de compressão pelo material herniado (Brisson, 2010). Já a meningoencefalite granulomatosa (MEG) é uma afecção inflamatória de sistema nervoso central (SNC) que leva a uma proliferação perivascular acentuada de células reticulo endoteliais. A doença é classificada como de curso rápido, idiopática e com provável envolvimento do sistema imune (Fenner et al., 2004). A doença aparece de forma subaguda e seus sinais clínicos são progressivos incluindo ataxia, head tilt, nistagmo, déficits de nervos cranianos, hipermetria e dor cervical (Muñana \& Luttgen, 1998).

Diante de um paciente com suspeita de transtorno neurológico, a identificação e o histórico são frequentemente úteis para chegar ao diagnóstico mais provável (Dewey \& Costa, 2016). Todavia, frequentemente há necessidade de se realizar outros exames que podem variar desde um simples hemograma até técnicas mais avançadas de diagnóstico como a Ressonância Magnética por exemplo (Dewey et al, 2017).

A fisioterapia veterinária é a especialidade médica que previne ou trata, via medidas fisioterápicas, a incapacidade física do indivíduo causada por dor, doença ou lesão (Henrique, 2020). O uso da reabilitação em pacientes com lesões neurológicas pode reduzir a incidência da eutanásia pois incentiva a plasticidade neural promovendo a melhora do indivíduo.

\section{Relato de caso}

Um cão macho, castrado da raça Pug com um ano e oito kg foi atendido na Clínica Nadja Jorge Neurologia Veterinária. No momento da consulta, foi observado dor, cifose, vocalização, dispneia, tetraparesia, tremores de cabeça e cegueira. Segundo o tutor, o quadro teve início um mês antes, sendo o primeiro sinal clínico déficit na acuidade visual. Ao exame físico neurológico, o paciente se apresentava em decúbito lateral com tetraparesia não ambulatória, espasticidade dos membros torácicos, dispneia importante com respiração paradoxal, vocalização e disfonia. Apresentava espasmos eventuais em região cervical, nível de consciência deprimido e comportamento delirante.

$\mathrm{Na}$ avaliação dos nervos cranianos encontrou-se resposta à ameaça ausente e anisocoria (II); reflexo pupilar fotomotor presente bilateralmente, reflexo oculocefálico presente bilateralmente, presença de estrabismo posicional ventro dorsal bilateral (III), assimetria de língua (XII) para o lado esquerdo com 
lentidão na movimentação da mesma, músculos mastigatórios simétricos e sem atrofia. Nas reações posturais, o paciente apresentou ausência da propriocepção e saltitamento nos quatro membros. Durante a avaliação dos reflexos segmentares, o paciente demonstrou diminuição de tônus muscular e do reflexo flexor. Os reflexos patelares, cutâneo do tronco e perineal estavam presentes. A nocicepção estava presente nos quatro membros.

Foram solicitados raio x (região cervical e toracolombar), hemograma, testes de função renal e hepática, ultrassom abdominal, eletrocardiograma e urinálise. No raio x, foi identificado uma mineralização do disco no espaço intervertebral de $\mathrm{C} 2-\mathrm{C} 3$; no ultrassom abdominal e urinálise foram encontradas alterações compatíveis com cistite bacteriana Inicialmente, instituiu- se tratamento para controle álgico e tratamento da cistite o qual consistia em dipirona 5 gotas a cada 8 horas por 5 dias, cloridrato de tramadol $80 \mathrm{mg} 1 / 4$ de comprimido a cada 8 horas por 10 dias, prednisolona $3 \mathrm{mg} / \mathrm{ml} 1,5 \mathrm{ml}$ a cada 24 horas por 10 dias, amoxicilina $50 \mathrm{mg} 1$ comprimido a cada 24 horas por 10 dias.

Foi solicitada que a ressonância magnética (RM) de encéfalo e da coluna cervical fosse realizada sete dias após o término da última medicação para evitar interferências na coleta do líquor. A ressonância magnética de encéfalo sugeriu possível foco de meningoencefalite em lobo piriforme. Na região medular cervical foi evidenciado hérnia de disco (Hansen tipo I) no espaço intervertebral C2-C3 com grande quantidade de material discal extruso, causando compressão medular importante (Figura 1). A coleta de líquor não foi realizada devido a impossibilidade de ventroflexionar a região cervical do paciente, pois o sujeitaria a complicações respiratórias e piora dos sinais clínicos neurológicos. Sendo assim, não foi possível diagnosticar a origem da encefalite.

Com o diagnóstico presuntivo de Meningoencefalomielite granulomatosa (MEG) e hérnia cervical Hansen tipo I, instituiu-se com o seguinte tratamento medicamentoso: Omeprazol 10mg 1/2 comprimido

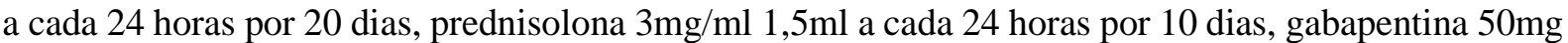
1 cápsula a cada 8 horas por 60 dias, e dipirona $25 \mathrm{mg} 5$ gotas a cada 8 horas por 10 dias. Recomendouse a troca de decúbito a cada 4 horas para evitar desconforto, escaras e sobrecarga pulmonar. O paciente foi encaminhado para avaliação do neurocirurgião (Figura 2) haja vista a necessidade de intervenção cirúrgica nos casos de extrusão de disco.

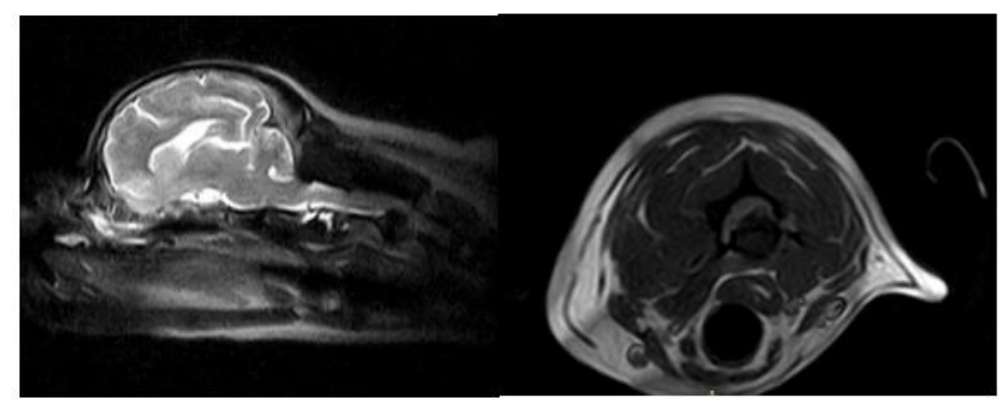

Figura 1. Imagem da Ressonância Magnética.

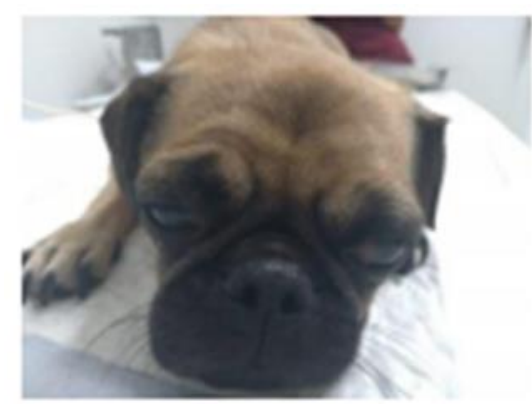

Figura 2. Paciente no momento da consulta com o cirurgião.

O neurocirurgião optou por realizar intervenção cirúrgica para descompressão medular por meio da técnica de slot cervical ventral (Figura 3 ) na qual, pode-se remover grande quantidade de conteúdo herniado. O paciente teve alta em bom estado de recuperação, sem dor e com ingestão hídrica e alimentar voluntária. A medicação pós operatória recomendada foi: Omeprazol $10 \mathrm{mg} 1$ cápsula a cada 24 horas por 15 dias; Ondasentrona $4 \mathrm{mg} \mathrm{1/4}$ de comprimido a cada 12 horas por 7 dias; Dipirona $25 \mathrm{mg} 5$ gotas a cada 8 horas por 3 dias; Cloridrato de tramadol $80 \mathrm{mg} \mathrm{1/4}$ de comprimido a cada 8 horas por 7 dias; Citoneurim ${ }^{\circledR} 50001$ comprimido a cada 24 horas por 60 dias; Ômega $3500 \mathrm{mg} 1$ comprimido a cada 24 horas por 60 dias.

O paciente foi encaminhado para reabilitação, dessa forma, iniciou as sessões de fisioterapia nove dias após o procedimento cirúrgico. O protocolo instituído foi: 2 sessões por semana durante 3 semanas antes da segunda avaliação. As sessões visavam controle de dor (Figura 4), estímulo a propriocepção, ganho de tônus muscular e treino neurolocomotor. O paciente apresentou maior controle de tronco, conseguindo se manter em posição esternal, após primeira semana de reabilitação. Durante a segunda semana, foi possível observar sustentação de peso nos quatro membros, embora apresentasse dificuldade 
em posicionar os membros torácicos. Ao final da terceira semana de tratamento, o paciente era apto a locomoção sem auxílio, contudo, apresentava leve dismetria e déficit proprioceptivo. Na quarta semana, foi realizada apenas uma sessão de fisioterapia devido à desistência do tutor.

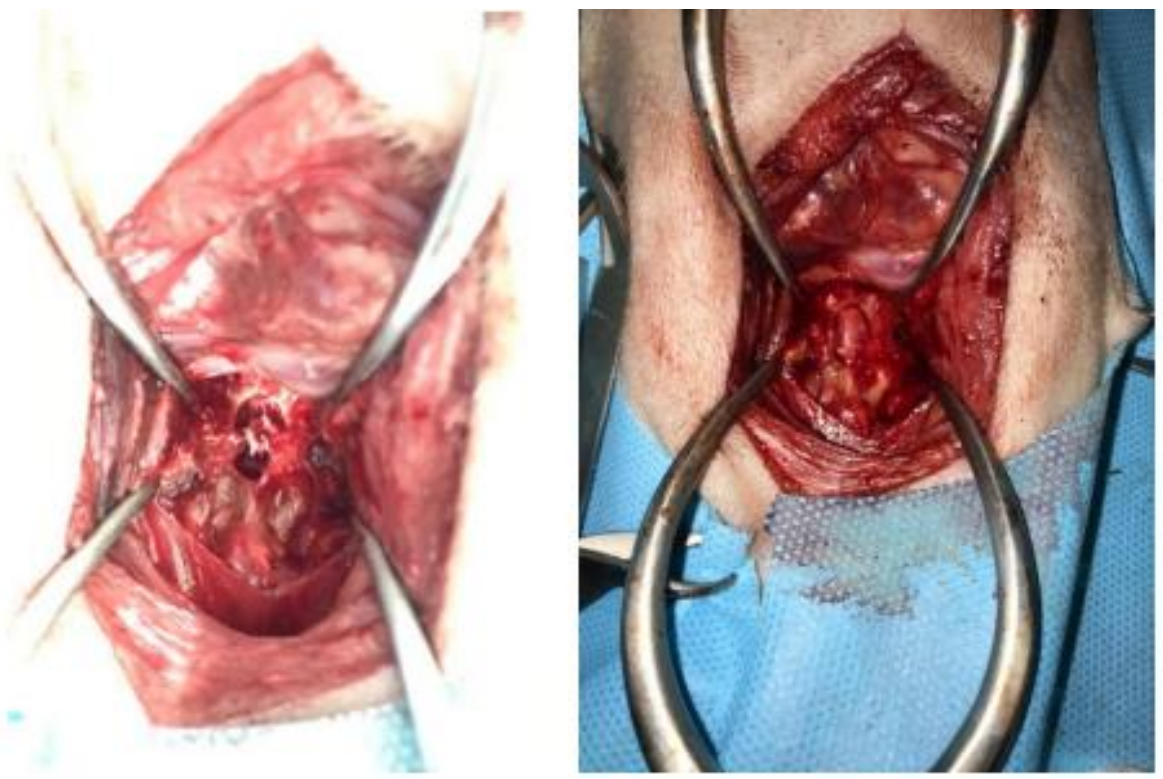

Figura 3. Imagem da técnica Slot Ventral.

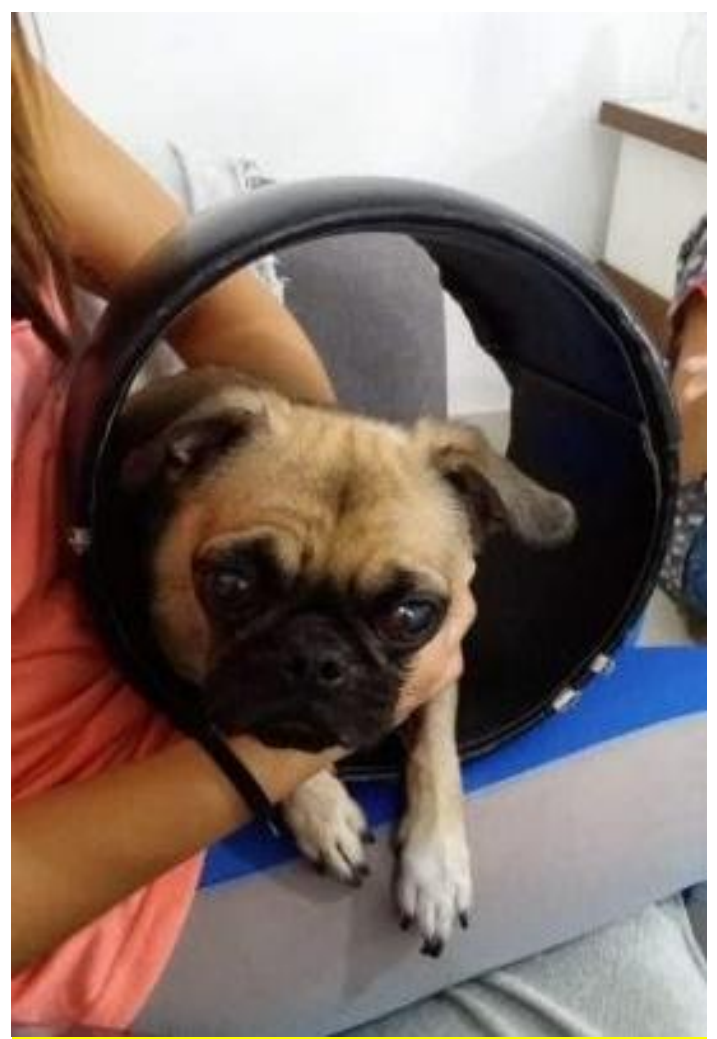

Figura 4. Paciente realizando magnetoterapia.

\section{Resultados e discussão}

Embora o paciente apresentasse um quadro típico de hérnia cervical Hansen tipo I (dor cervical, déficits proprioceptivos nos quatro membros e dificuldade respiratória) (Dewey \& Costa, 2016), a evolução lenta do quadro (iniciado 30 dias antes) e presença de outras alterações como déficits visuais e tremores de cabeça fizeram com que um check-up fosse realizado para que a causa desses problemas fosse devidamente determinada (Dewey \& Costa, 2016; Henrique, 2020). Com isso, foi realizada uma 
série de exames incluindo hemograma, ultrassom abdominal e raio x. Identificou-se no ultrassom abdominal alterações condizentes com cistite bacteriana como conteúdo anecóico com ecos puntiformes em suspensão. No raio x cervical e toracolombar, foi visualizado mineralização do disco intervertebral em C2-C3 sem evidências radiográficas de comprometimento medular.

No exame de RM, foram encontradas as seguintes alterações: no encéfalo moderado hipersinal amorfo de limites parcialmente definidos nas sequências ponderadas em T2 e FLAIR, isso-intenso em T1, não captante de contraste paramagnético e que apresenta sutil efeito de massa local, é observada no lobo piriforme esquerdo, acometendo principalmente a substância cinzenta; C2-3: material hipo-intenso nas sequências ponderadas em T2 e 3DHyce, de provável origem do núcleo pulposo discal, é observado na região ventrolateral esquerda do canal vertebral, causando grave com pressão da medula espinhal. As impressões diagnósticas foram: Lesão intra-axial centrada no lobo piriforme esquerdo, com o descrito acima, considerando o histórico clínico, raça e idade do paciente, o principal diagnóstico diferencial processo inflamatório/infeccioso como meningoencefalite de origem não determinada, como em meningoencefalite granulomatosa. 2. C2-3: Extrusão discal, ventrolateral esquerda, causando grave compressão da medula espinhal. A análise do líquor cefalorraquidiano não foi realizada devido à presença da hérnia C2-C3 e pela sugestão de hipertensão na imagem craniana (Cherubini et al., 2006; Cornelis et al., 2017).

A impossibilidade de concluir a causa de encefalite no paciente não permitiu um tratamento específico para tal enfermidade; porém após a realização da cirurgia slot cervical ventral, o animal teve uma evolução muito satisfatória do quadro neurológico, indicando assim que a principal causa da tetraparesia era a presença da compressão entre C2-C3.

A realização da cirurgia slot cervical ventral é a terapia de escolha nos casos de extrusão cervical única ou em espaços alternados. São pacientes candidatos à intervenção cirúrgicas aqueles que apresentarem: episódios recorrentes de dor ou dor irresponsiva ao tratamento medicamentoso, déficits neurológicos moderados a graves (tetraparesia não ambulatória) ou piora do quadro neurológico mesmo

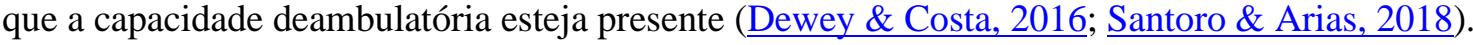

O protocolo fisioterápico foi dividido em três fases: fase 1: Controle de dor e preparação para o movimento; fase 2: Coordenação motora e fase 3: Força muscular e agilidade (Henrique, 2020). Essa divisão é importante pois respeita o tempo de cicatrização tecidual principalmente e da evolução clínica do paciente.

Na Fase Controle de Dor e Preparação para o Movimento, escolheu-se o FES em ponto motor para aquecimento da musculatura do infra-espinhoso e supra espinhoso. A frequência escolhida de $10 \mathrm{hz}$ aumenta o fluxo sanguíneo na musculatura (Agne, 2018). Após o aquecimento muscular, iniciou-se o trabalho de neuro-reabilitação funcional. O exercício escolhido foi paciente em quatro apoio em cima do disco de equilíbrio a bola terapêutica servindo de suporte com o objetivo de estimular os feixes descendentes vestíbulos espinhais (Martins \& Ferreira, 2018; Ramalho et al., 2015). O objetivo do uso do campo magnético foi controle de dor pois ele promove a liberação de endorfinas e de moduladores da dor na frequência e tempo utilizados (Lewicki \& Valim, 2020).

$\mathrm{Na}$ fase 2, Coordenação Motora, introduziu-se o treino neuro locomotor em hidro esteira. A caminhada na hidro esteira melhora a força, resistência muscular, amplitude de movimento e agilidade, enquanto minimiza a dor (Levine et al., 2004) além de estimular a coordenação motora e equilíbrio pois, o andar no hidroesteira provoca uma leve turbulência e essa instabilidade é um estímulo importante (Henrique, 2020). Quanto maior a altura da água mais fácil e confortável é para o paciente manter-se em estação (Henrique, 2020; Levine et al., 2004).

Com a evolução clínica do paciente (o mesmo passou a deambular sozinho), iniciou-se a Fase 3 do tratamento onde o exercício de escolha foi a caminhada sobre os cavaletes. Tal exercício aprimora a propriocepção, fortalece os músculos flexores e amplia a passada (McCauley \& Van Dyke, 2013).

$\mathrm{Na}$ reavaliação feita após 30 dias da primeira consulta neurológica (Figura 5), o paciente apresentou nível de consciência e comportamento normais, bem como melhora do tônus muscular e do reflexo flexor, que antes estava diminuído. Pode-se observar também, ausência de dispneia ou dor epaxial. Embora apresentasse leve dismetria, houve recuperação locomotora significativa. A respeito da avaliação de nervos cranianos, os testes foram normalizados com exceção a resposta à ameaça diminuída 
e presença de estrabismo posicional ventro dorsal em ambos os olhos. O tutor foi orientado a manter as sessões de fisioterapia. As seguintes medicações foram mantidas: Omeprazol $10 \mathrm{mg} 1$ cápsula a cada 24 horas durante 15 dias, gabapentina $50 \mathrm{mg} 1$ cápsula a cada 8 horas até completar 60 dias; ômega 3500 mg a cada 24 horas até completar 60 dias.

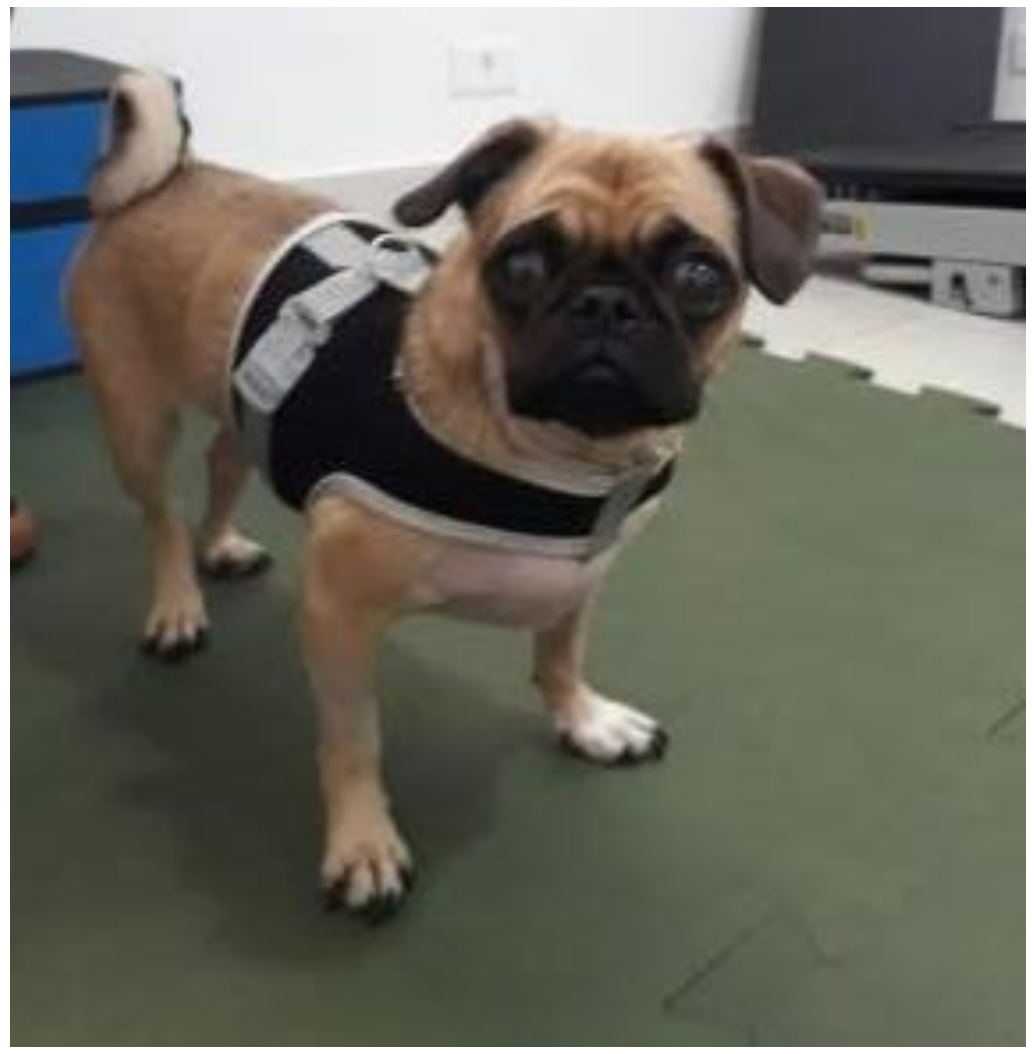

Figura 5. Paciente após 30 dias pós cirúrgico. Imagem gentilmente cedida pela médica veterinária fisiatra Daniela Loureiro Henrique.

\section{Conclusão}

A fisioterapia veterinária foi crucial no processo de reabilitação do paciente após procedimento cirúrgico de slot ventral cervical pois promoveu incremento na deambulação normal ao estimular a musculatura através da execução de exercícios voltados para fortalecimento, equilíbrio e coordenação motora.

\section{Referências bibliográficas}

Agne, J. E. (2018). Fortalecimento muscular com corrente Aussie, Russa, FES e NMES In: Eletrotermofototerapia. 5 ed. Editora Pallotti, Santa Maria. 166-214.

Brisson, B. A. (2010). Intervertebral disc disease in dogs. The Veterinary Clinics of North America. Small Animal Practice, 40(5), 829-858. DOI: 10.1016/j.cvsm.2010.06.001

Cherubini, G. B., Platt, S. R., Anderson, T. J., Rusbridge, C., Lorenzo, V., Mantis, P., \& Cappello, R. (2006). Characteristics of magnetic resonance images of granulomatous meningoencephalomyelitis in 11 dogs. Veterinary Record, 159(4), 110-115. DOI: http://dx.doi.org/10.1136/vr.159.4.110

Cornelis, I., Volk, H. A., Van Ham, L., \& De Decker, S. (2017). Clinical presentation, diagnostic findings and outcome in dogs diagnosed withpresumptive spinal-only meningoen-cephalomyelitis of unknown origin. Journal of Small Animal Practice, 58(3), 174-182. DOI: https://doi.org/10.1111/jsap.12622

Dewey, C. W., \& Costa, R. C. (2016). Practical guide to canine and feline neurology (3 Ed.). Wiley Blackwell.

Fenner, W. R., Ettinger, S. J., \& Feldman, E. C. (2004). Doenças do cérebro. Tratado de Medicina Interna Veterinária: Doenças Do Cão e Do Gato, 1, 586-638. 
Hansen, H.-J. (1952). A pathologic-anatomical study on disc degeneration in dog: With special reference to the so-called enchondrosis intervertebralis. Acta Orthopaedica Scandinavica, 23(Sup 11), 1-130. DOI: https://doi.org/10.3109/ort.1952.23.suppl-11.01

Henrique, D. L. (2020). Exercícios terapêuticos. In F. Vituri \& D. L. Henrique (Eds.), Fisioterapia em pequenos nimais (pp. 95-102). Editora Payá.

Levine, D., Rittenberry, L., \& Millis, D. L. (2004). Aquatic therapy. In D. L. Millis, D. Levine, \& R. T. Taylor (Eds.), Canine rehabilitation \& physical therapy (pp. 264-276). Elselvier Saunders.

Lewicki, V., \& Valim, M. M. (2020). Agentes físicos na reabilitação veterinária. In F. Vituri \& D. L. Henrique (Eds.), Fisioterapia em pequenos animais (pp. 69-79). Editora Payá.

Martins, A., \& Ferreira, A. (2018). Neuroreabilitação funcional em lesões medulares. In R. S. Lopes \& R. Diniz (Eds.), Fisiatria em pequenos animais (pp. 287-298). Intelgente.

McCauley, L., \& Van Dyke, J. B. (2013). Therapeutic exercise. In M. C. Zink \& J. B. Van Dyke (Eds.), Canine sports medicine and rehabilitation (pp. 132-157). John Wiley \& Son Inc.

Muñana, K. R., \& Luttgen, P. J. (1998). Prognostic factors for dogs with granulomatous meningoencephalomyelitis: 42 cases (1982-1996). Journal of the American Veterinary Medical Association, 212(12), 1902-1906.

Ramalho, F. P., Formenton, M. R., Isola, J. G. M. P., \& Joaquim, J. F. G. (2015). Tratamento de doença de disco intervertebral em cão com fisioterapia e reabilitação veterinária: relato de caso. Revista de Educação Continuada Em Medicina Veterinária e Zootecnia Do CRMV-SP, 13(1), 10-17. DOI: https://doi.org/10.36440/recmvz.v13i1.25561

Santoro, M. B., \& Arias, M. V. B. (2018). Complicações observadas em cães e gatos com doenças neurológicas. Pesquisa Veterinária Brasileira, 38(6), 1159-1171. DOI: https://doi.org/10.1590/1678-5150-pvb-4968

Taylor, S. M. (2015). Distúrbios da Medula Espinhal. In R. W. Nelson \& C. G. Couto (Eds.), Medicina Interna de Pequenos Animais (pp. 1048-1072). Elsevier Brasil.

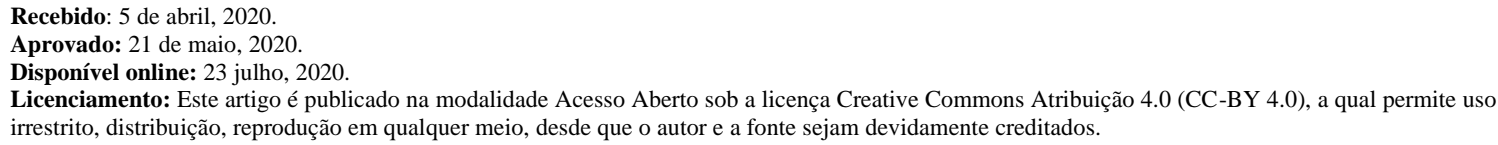

Licenciamento: Este artigo é publicado na modalidade Acesso Aberto sob a licença Creative Commons Atribuição 4.0 (CC-BY 4.0), a qual permite uso irrestrito, distribuição, reprodução em qualquer meio, desde que o autor e a fonte sejam devidamente creditados. 